\title{
DESEMPENHO E QUALIDADE DE OVOS DE CODORNAS JAPONESAS ALIMENTADAS COM DIFERENTES RAÇÕES COMERCIAIS
}

\author{
Jorge Cunha Lima Muniz¹, Sérgio Luiz de Toledo Barreto ${ }^{1}$, Gabriel da Silva Viana ${ }^{1}$, Renata de Souza \\ Reis $^{2}$,Raquel Mencalha ${ }^{3}$, Lívia Maria dos Reis Barbosa ${ }^{1}$, Roberta Corsino Ferreira ${ }^{1}$
}

\begin{abstract}
RESUMO - Objetivou-se avaliar, com o presente estudo, o desempenho e a qualidade de ovos de codornas japonesas alimentadas com três diferentes rações comerciais e verificar os valores de proteína bruta, cálcio, fósforo e extrato etéreo das mesmas. Foram utilizadas 126 aves com 157 dias de idade, distribuídas em delineamento inteiramente casualizado constituído de três tratamentos (rações comerciais: A, B e C), seis repetições e sete aves por unidade experimental. Para a avaliação dos níveis de garantia presentes nas três rações, determinou-se os teores de proteína bruta (PB), cálcio (Ca), fósforo (P) e extrato etéreo (EE). Os parâmetros avaliados foram consumo de ração (CR), produção de ovos (PR), peso do ovo (PO), massa de ovos (MO), conversão alimentar por massa de ovos (CAMO), conversão alimentar por dúzia de ovos (CADZ), gravidade específica (GE), percentagem de gema (G), albúmen (A), casca (C) e de ovos comercializáveis (OC). Os valores avaliados de Ca e EE estão de acordo com os divulgados pelas rações comerciais. Para os valores avaliados de $\mathrm{P}$ na ração A e de $\mathrm{PB}$ nas rações $\mathrm{B}$ e $\mathrm{C}$ estão abaixo dos valores divulgados. Não foram observadas diferenças $(\mathrm{P}>0,05)$ para PR, PO, MO, GE, C e OC. Houve efeito significativo $(\mathrm{P}<0,01)$ para o $\mathrm{CR}$, sendo a ração A menos consumida pelas codornas e juntamente com a produção de ovos obteve-se melhor valor $(\mathrm{P}<0,01)$ de conversão alimentar por massa de ovos, conversão alimentar por dúzia de ovos e maior porcentagem $(\mathrm{P}<0,05)$ de gema e de albúmen. Conclui-se que a Ração $\mathrm{A}$ possibilitou melhor desempenho das aves mantendo a qualidade dos ovos das mesmas, além de apresentar valores de PB, Ca e EE dentro dos limites divulgados pela empresa em comparação com as outras marcas de ração testadas.
\end{abstract}

Palavras chave: Coturnix coturnix, matriz nutricional, produção de ovos.

\section{PERFORMANCE AND EGGS QUALITY OF JAPANESE QUAILS FED WITH DIFFERENT COMMERCIAL RATIONS}

\begin{abstract}
The aim with this study was to evaluate the performance and the quality of Japanese quails fed with three different commercial feed and check the values of crude protein, calcium, phosphorus and ether extract of them. It was used 126 birds with 157 days of age, distributed in a completely randomized design consisting of three treatments (commercial diets: $A, B$ and $C$ ), six replicates and seven birds each. For the assessment of collateral levels present in the three rations, it was determined the crude protein (CP), calcium $(C a)$, phosphorus $(P)$ and ether extract (EE). We evaluated feed intake (FI), egg production (EP), egg weight (EW), egg mass (EM), feed conversion per egg mass (FCEM), feed conversion per dozen eggs (FCDE), specific gravity ( $S G)$, percentage of yolk $(Y)$, albumen $(A L)$, bark $(B A)$ and commercial egg production (CEP). The values assessed for Ca and EE are consistent with those disclosed by commercial pet food. The values assessed for $P$ in ration $A$ and $C P$ in the rations $B$ and $C$ are below the published values. It was not observed difference $(P>0.05)$ for EP, EW, EM, SG, BA and CEP. There was significant effect $(P<0.01)$ for the FI, and the ration A was less consumed by quails and together with the production of eggs it was obtained best value $(P<0.01)$ for FCEM, FCDE and higher percentage $(P<0.05)$ of $Y$ and $A L$. It follows that feed the best possible performance of maintaining the quality of poultry eggs thereof, and present values of CP, Ca and EE within the limits disclosed by the company compared with the other tested commercial diets.
\end{abstract}

Keywords: Coturnix coturnix, egg production, nutritional matrix.

\footnotetext{
${ }^{1}$ Universidade Federal de Viçosa - Departamento de Zootecnia, s/n, Campus Universitário, Viçosa-MG. jorge.limamuniz@ hotmail.com 2 Universidade Federal de São João Del Rei.

${ }^{3}$ Universidade Federal de Lavras.
} 


\section{INTRODUÇÃO}

A coturnicultura exerce importante papel na avicultura industrial, sendo o setor que obteve maior desenvolvimento nos últimos tempos. Os recentes estudos em sanidade, ambiência, nutrição e a crescente tecnificação das granjas produtoras de codornas contribuíram de forma significativa para esse desenvolvimento.

Segundo IBGE (2013) a produção de ovos de codorna em 2013 foi de 342,5 milhões de dúzias, equivalente a um aumento de $23,9 \%$ em relação ao volume registrado em 2011. Este aumento exponencial de aves alojadas indica a crescente demanda por produtos oriundos da atividade. Dentre estes produtos, os ovos são os principais responsáveis, visto que o aumento da procura por refeições prontas promoveu a expansão de estabelecimentos comerciais de maior utilização de ovos de codorna, como restaurantes do tipo self-service e churrascarias (Costa, 2010). Entretanto, alguns elos fracos na coturnicultura, como a genética não estabelecida juntamente com a nutrição, ainda se caracterizam como entraves para um maior crescimento da atividade (Reis et al., 2012).

A quantidade mínima de nutrientes depende da natureza e da qualidade dos alimentos disponíveis, além do conhecimento da digestibilidade das fontes e das exigências nutricionais. Contudo, os preços dos ingredientes utilizados para formulação das rações, muitas vezes completam as informações para a decisão dos níveis a serem usados. Essas alternâncias observadas nos preços dos ingredientes podem fazer com que os níveis dos nutrientes também flutuem na dieta comprometendo a produção. Desta forma, o presente estudo teve como objetivo avaliar os níveis de garantia de diferentes rações comerciais, e sua influência sobre o desempenho e qualidade de ovos de codornas japonesas.

\section{MATERIAL E MÉTODOS}

O experimento foi conduzido no setor de Avicultura do Departamento de Zootecnia da Universidade Federal de Viçosa (UFV). Utilizaram-se 126 codornas japonesas (Coturnix coturnix japonica) com 157 dias de idade por um período de 63 dias. As mesmas foram alojadas em galpão de alvenaria e distribuídas em gaiolas de arame galvanizado fornecendo área de $106 \mathrm{~cm}^{2} /$ ave. Sobre o piso de cimento, abaixo das gaiolas, foi colocada uma camada de maravalha, para absorção da umidade das excretas. O comedouro utilizado foi do tipo calha em chapa galvanizada e o bebedouro do tipo automático um para cada duas gaiolas. Utilizou-se o delineamento inteiramente casualizado (DIC) constituído por três tratamentos, representados por três tipos de rações comerciais (A, B e C), seis repetições e sete aves por unidade experimental. A fim de preservar a integridade das empresas responsáveis por suas respectivas marcas, se optou denominá-las, de forma aleatória, de Ração A, Ração B e Ração C.

As rações e a água foram fornecidas à vontade. Adotou-se o programa de luz de 16 horas de luz diárias (natural + artificial), com controle por um relógio automático (timer). As temperaturas de máxima e mínima e a umidade relativa do ar foram registradas diariamente por meio de termômetros de máxima e mínima e de bulbo seco e bulbo úmido, localizados à altura das gaiolas, ou seja, 1,5 metros do piso.

Para a avaliação dos níveis de garantia das rações comerciais foi mensurado o teor de cálcio, fósforo $(\mathrm{P})$, proteína bruta $(\mathrm{PB})$ e extrato etéreo $(\mathrm{EE})$ por meio de análises bromatológicas descritas por Silva \& Queiroz (2002). Para a análise de Ca e P foi utilizada uma solução mineral, preparada conforme os procedimentos da via úmida, dessa solução foram determinados os teores de $\mathrm{P}$, pelo método colorimétrico, e de $\mathrm{Ca}$, pelo método de absorção atômica. Os valores de EE foram obtidos através de extração por éter de petróleo seguindo o método a quente. A digestão, destilação e titulação são procedimentos contidos no método de nitrogênio total utilizado para obtenção dos teores de PB. Para comparação dos dados obtidos para essas análises, foi utilizada a estatística descritiva.

Os parâmetros estudados para desempenho e qualidade dos ovos foram: consumo de ração (g/ave/ dia), produção de ovos (\%), peso do ovo (g), massa de ovos (g/ave/dia), conversão alimentar por massa de ovos (kg de ração/kg de ovos), conversão alimentar por dúzia de ovos (kg de ração/ dúzia de ovos), gravidade específica $\left(\mathrm{g} / \mathrm{cm}^{3}\right)$, percentagem de gema, albúmen e casca e percentagem de ovos comercializáveis. Os resultados obtidos desses parâmetros foram submetidos a análises estatísticas utilizando-se o programa Sistema para Análises Estatísticas e Genéticas (SAEG) desenvolvido pela Universidade Federal de Viçosa UFV (2007). Na ocorrência de efeito significativo as 
Tabela 1 - Características descritas nos rótulos das rações comerciais utilizadas

- Composição básica do produto

Ração A

Milho integral moído, glúten de milho, farelo de soja cloreto de sódio (sal comum), calcário calcítico, farinha de carne e ossos, fosfato bicálcico, premix vitamínico mineral.

- Enriquecimento por $\mathrm{kg}$ do produto

Ácido fólico - $3 \mathrm{mg}$, ácido pantotênico - $17 \mathrm{mg}$, colina - $48 \mathrm{mg}$, cobre - 36,75 mg, ferro - $25 \mathrm{mg}$, iodo - 0,36 mg, manganês - 38,50 mg, selênio - 0,30 mg, vitamina A - 6000,00 ui, vitamina B1 - 1,20 mg, vitamina B12 - 7,00 p. p. b., vitamina B2 - 3,60 mg, vitamina b6 - 2,00 mg, vitamina D3 - 1800,00 ui, vitamina e - 6,00 ui, vitamina $\mathrm{K}$ - 1,50 mg, vitamina pp - 17,00 mg, zinco - $25 \mathrm{mg}$.

- Níveis de garantia

Umidade (máx.) 13\%, proteína bruta (min.) 21\%, extrato etéreo (min.) 3\%, matéria fibrosa (máx.) 3,8\%, matéria mineral (máx.) $12,7 \%$, cálcio (máx.) $4 \%$, fósforo (min.) $0,7 \%$.

- Composição básica do produto

\section{Ração B}

Milho integral moído, farelo de soja, farelo de trigo, farelo de gérmen de milho, farelo de gérmen de milho desengordurado, farinha de carne, cloreto de sódio (sal comum) calcário calcítico, fosfato bicálcico, premix vitamínico, mineral aminoácido.

- Enriquecimento por $\mathrm{kg}$ de produto

Vitamina A - 4.200 U.I., vitamina D3 - 1.050 U.I., vitamina E - $4 \mathrm{mg}$, vitamina K3 - 0,90 mg, tiamina (B1) - 0,3 mg, riboflavina (B2) $-2 \mathrm{mg}$, piridoxina (B6) $-0,6 \mathrm{mg}$, vitamina B $12-3,6 \mathrm{mcg}$, niacina $-9 \mathrm{mg}$, ácido fólico - $0,18 \mathrm{mg}$, pantotenato de cálcio $-4 \mathrm{mg}$, colina $-300 \mathrm{mg}$, metionina $-4 \mathrm{~g}$, cobre $-6 \mathrm{mg}$, ferro $-30 \mathrm{mg}$, iodo $-0,8 \mathrm{mg}$, manganês $-65 \mathrm{mg}$, selênio $-0,2 \mathrm{mg}$, zinco $-50 \mathrm{mg}$.

- Níveis de garantia

Umidade (máx.) 13\%, proteína bruta (mín.) 20\%, extrato etéreo (mín.) 2,5\%, matéria fibrosa (máx.) 6\%, matéria mineral (máx.) $22 \%$, cálcio (máx.) 4,2\%, pósforo (mín.) $0,55 \%$.

\section{- Composição básica do produto}

Ração C

Bacitracina de zinco, calcário calcítico, cloreto de colina, cloreto de sódio (sal comum), farelo de glúten de milho 21, farelo de soja, farelo de trigo, farinha de carne e ossos, L-lisina, DL-metionina, milho integral moído, sorgo integral moído, premix mineral, premix vitamínico.

- Enriquecimento por $\mathrm{kg}$ de produto

Ácido fólico - 0,25 mg, ácido pantotênico - $6 \mathrm{mg}$, bacitracina de zinco - $100 \mathrm{mg}$, cobre $-8 \mathrm{mg}$, colina - $400 \mathrm{mg}$, ferro $-50 \mathrm{mg}$, iodo $-0,75 \mathrm{mg}$, lisina $-2.000 \mathrm{mg}$, manganês $-75 \mathrm{mg}$, metionina $-1.500 \mathrm{mg}$, niacina $-16 \mathrm{mg}$, selênio - 0,25 $\mathrm{mg}$, vitamina A - 7.200 u.i., vitamina B1 - $1 \mathrm{mg}$, vitamina B12 - $7 \mathrm{mcg}$, vitamina B2 - $3 \mathrm{mg}$, vitamina B6 - 1,5 mg, vitamina D3 - 1.600 u.i., vitamina $\mathrm{E}-5 \mathrm{mg}$, vitamina $\mathrm{K} 3-1 \mathrm{mg}$, zinco $-50 \mathrm{mg}$.

- Níveis de garantia

Umidade (máx.) 12\%, proteína bruta (mín.) 19\%, extrato etéreo (mín.) 2,5\%, matéria fibrosa (máx.) 4\%, matéria mineral (máx.) 14\%, cálcio (máx.) 4\%, fósforo (mín.) 0,5\%.

médias de cada tratamento foram comparadas pelo teste de SNK ao nível de 5\% de probabilidade.

\section{RESULTADOS E DISCUSSÃO}

As médias das temperaturas registradas de máxima e mínima foram, respectivamente, $28,07 \pm 2,7^{\circ} \mathrm{C}$ e 24,20 $\pm 1,3^{\circ} \mathrm{C}$. Desta forma, com base nas temperaturas de conforto (entre 32 a $22^{\circ} \mathrm{C}$ ) sugeridas por Murakami \& Garcia (2010) para codornas japonesas na fase adulta, pode-se inferir que durante o período experimental as aves estiveram em conforto térmico.

Verificou-se que os valores obtidos de Ca nas diferentes rações comerciais, foram condizentes com os valores avaliados em seus respectivos rótulos (Tabela 2). O mesmo foi observado para o fósforo, nas rações B e C, enquanto a ração comercial A apresentou o valor obtido deste mineral $27,14 \%$ abaixo do valor divulgado pela empresa.

Para as codornas de postura o Ca e o P são considerados os principais minerais suplementados às rações na ração, tendo em vista sua expressiva participação no metabolismo e na qualidade da casca do ovo. Contudo, níveis inadequados destes minerais na alimentação podem ocasionar desequilíbrio na homeostase mineral, além do desenvolvimento inapropriado dos ossos de codornas e da formação 
Tabela 2 - Valores divulgados pelas empresas (VD) comparados aos valores avaliados (VA) das análises bromatológicas de proteína bruta $(\mathrm{PB})$, cálcio $(\mathrm{Ca})$, fósforo $(\mathrm{P})$ e de extrato etéreo (EE) das rações comerciais utilizadas na alimentação de codornas japonesas em fase de produção

\begin{tabular}{|c|c|c|c|c|c|c|}
\hline \multirow{3}{*}{ Análises (\%) } & \multicolumn{6}{|c|}{ Rações comerciais } \\
\hline & \multicolumn{2}{|c|}{ A } & \multicolumn{2}{|c|}{ B } & \multicolumn{2}{|c|}{$\mathrm{C}$} \\
\hline & VD & VA & VD & VA & VD & VA \\
\hline $\mathrm{Ca}$ & 4,00 & 2,59 & 4,20 & 3,76 & 4,00 & 4,29 \\
\hline $\mathrm{P}$ & 0,70 & 0,51 & 0,55 & 0,97 & 0,50 & 0,77 \\
\hline $\mathrm{PB}$ & 21,00 & 20,72 & 20,00 & 18,12 & 19,00 & 18,09 \\
\hline $\mathrm{EE}$ & 3,00 & 3,44 & 2,50 & 7,74 & 2,50 & 4,32 \\
\hline
\end{tabular}

VD referente à PB, P e EE são valores apresentados por níveis mínimos considerados. VD referente ao Ca são valores apresentados por níveis máximos considerados.

da casca dos ovos com baixa qualidade (Pastore et al., 2012).

Houve diferença entre os valores divulgados e avaliados referentes à $\mathrm{PB}$ das rações $\mathrm{B}$ e $\mathrm{C}$, sendo os valores obtidos, inferiores aos valores divulgados pelas marcas em $9,4 \%$ e $4,78 \%$, respectivamente. No entanto, a ração $\mathrm{A}$ foi a menos discrepante, por apresentar a menor diferença entre o valor avaliado e o divulgado de PB, sendo esta de $1,33 \%$. A dieta para as aves deve garantir os aminoácidos essenciais, e um nível adequado de PB para assegurar um satisfatório "pool" de nitrogênio para a síntese de aminoácidos para formação, principalmente, da gema e do albúmen no ovo (NRC, 1994).

Segundo Jordão Filho et al. (2006), níveis marginais de PB, promovem redução no crescimento e produção de ovos, por conta do desvio de parte desta para funções menos vitais, prejudicando assim o desenvolvimento corporal e a produção. Já o seu excesso pode limitar o desempenho das aves, pois o catabolismo aminoacídico requer gasto extra de energia para excreção de nitrogênio na forma de ácido úrico.

Observou-se que todas as três marcas de ração apresentaram valores de EE superiores aos valores mínimos recomendados, conforme indicado por seus respectivos rótulos. No entanto, a eficiência de utilização da energia do alimento para a produção de ovos e ganho de peso pelas codornas pode diminuir conforme aumenta a densidade energética da dieta, ou alternativamente, a quantidade de energia requerida por ovo produzido pode aumentar à medida que o nível energético por quilograma da dieta é aumentado (Pecuri \& Coon, 1991). Segundo Ost \& Peixoto (2000), tal fato pode provocar piora na conversão alimentar de codornas.
A eficiência de utilização dos nutrientes depende do metabolismo de muitos compostos, envolvendo grande número de reações controladas por enzimas, as quais, estão sob controle genético (Neshein, 1966). Para que as aves expressem seu potencial genético é necessário que elas estejam adequadamente nutridas, o que é possível quando são supridas suas exigências nutricionais mínimas.

Apesar das três marcas de rações apresentarem grande parte dos valores divulgados dos níveis de garantia similares aos avaliados, atualmente sabe-se através de inúmeros trabalhos na área (Vieira et al., 2012; Nery et al., 2013), que estes níveis podem ser alterados, a fim de, proporcionar uma melhor relação custo/benefício, maximizando a produção e diminuindo o custo da atividade.

Verificou-se influência das rações comerciais sobre o CR $(\mathrm{P}<0,01)$. As aves alimentadas com a ração A apresentaram menor consumo de ração quando comparadas aos demais tratamentos. No entanto, não houve influência $(\mathrm{P}>0,05)$ das diferentes marcas sobre a PR, PO, MO, GE e PC.

Embora não tenha sido observada diferença $(\mathrm{P}>0,05)$ para a PR, verificou-se que as aves alimentadas com a ração A obtiveram, em valores absolutos, $\mathrm{PR}$ superior de $6,8 \%$ e $9,1 \%$ quando comparada àquela obtida para as aves que receberam a ração $\mathrm{B}$ e $\mathrm{C}$, respectivamente. Isto contribuiu tanto para obtenção da melhor CAMO, quanto da melhor CADZ $(\mathrm{P}<0,01)$.

A PG e PA apresentou efeito significativo $(\mathrm{P}<0,01)$ em função das rações comerciais utilizadas, onde o maior valor foi observado nos ovos das aves alimentadas com a ração comercial A. A redução na PG, observado nos outros tratamentos, pode estar associada à diminuição 
Tabela 3 - Consumo de ração (CR), produção de ovos (PR), peso do ovo (PO), massa de ovos (MO), conversão alimentar por massa de ovos (CAMO), conversão alimentar por dúzia de ovos (CADZ), gravidade especifica (GE), percentagem de gema (PG), albúmen (PA) e casca (PC) e percentagem de ovos comercializáveis (OC) de codornas japonesas alimentadas com diferentes rações comerciais

\begin{tabular}{lcccc}
\hline \multirow{2}{*}{ Parâmetros } & \multicolumn{3}{c}{ Rações Comerciais } & \multirow{2}{*}{ CV $^{1}$} \\
\cline { 2 - 4 } & $\mathrm{A}$ & $\mathrm{B}$ & $\mathrm{C}$ & $(\%)$ \\
\hline $\mathrm{CR}(\mathrm{g} / \mathrm{ave} / \mathrm{dia})^{*}$ & $24,9 \mathrm{~b}$ & $26,7 \mathrm{a}$ & $27,7 \mathrm{a}$ & 4,25 \\
$\mathrm{PR}(\%)^{\mathrm{ns}}$ & 83,52 & 78,17 & 76,53 & 6,72 \\
$\mathrm{PO}(\mathrm{g})^{\mathrm{ns}}$ & 11,21 & 11,20 & 11,32 & 2,86 \\
$\mathrm{MO}(\mathrm{g} / \mathrm{ave} / \mathrm{dia})^{\mathrm{ns}}$ & 9,34 & 8,76 & 8,65 & 6,22 \\
$\mathrm{CAMO}(\mathrm{kg} / \mathrm{kg})^{*}$ & $2,67 \mathrm{~b}$ & $3,06 \mathrm{a}$ & $3,22 \mathrm{a}$ & 7,63 \\
$\mathrm{CADZ}(\mathrm{kg} / \mathrm{dz})^{*}$ & $0,36 \mathrm{~b}$ & $0,41 \mathrm{a}$ & $0,43 \mathrm{a}$ & 8,54 \\
$\mathrm{GE}\left(\mathrm{g} / \mathrm{cm}^{3}\right)^{\mathrm{ns}}$ & 1,076 & 1,074 & 1,075 & 0,16 \\
$\mathrm{PG}(\%)^{*}$ & $31,08 \mathrm{a}$ & $29,54 \mathrm{~b}$ & $29,97 \mathrm{~b}$ & 3,24 \\
$\mathrm{PA}(\%)^{*}$ & $62,15 \mathrm{a}$ & $61,03 \mathrm{~b}$ & $61,09 \mathrm{~b}$ & 2,24 \\
$\mathrm{PC}(\%)^{\mathrm{ns}}$ & 8,30 & 7,87 & 8,07 & 4,32 \\
OC $(\%)^{\mathrm{ns}}$ & 74,4 & 72,45 & 70,51 & 8,62 \\
\hline
\end{tabular}

${ }^{1}$ Coeficiente de variação; *Médias seguidas de letras iguais nas mesmas linhas, não diferem entre si pelo teste Student Newman Keuls ( $\mathrm{P}>0,05)$;

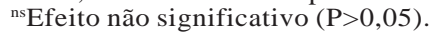

do nível de glicina + serina das rações comerciais conforme o nível de PB foi reduzido.

A gema é constituída por dois grandes grupos de fosfoproteínas constituídas em mais de 50\% de sua composição por resíduos de serina associados a ésteres fosfatos (Matsubara \& Sawano, 1995). Além disso, segundo Viana et al. (2014), a síntese das proteínas que constituem o albúmen ocorre em um período médio de 3 horas de duração, o que demanda adequado aporte de aminoácidos e proteína para a formação do albúmen em um curto período de tempo. A redução no teor de $\mathrm{PB}$ das rações pode resultar em decréscimo na concentração de aminoácidos no sangue, influenciando negativamente a síntese proteica no magno, de maneira a explicar a piora na PA das aves alimentadas com menor teor de PB. Estes resultados corroboram com os observados por Lima et al. (2014), que em estudo sobre exigência de PB para codornas japonesas, verificaram redução no peso da gema e albúmen dos ovos de codornas alimentadas com níveis inferiores de PB.

Mediante os resultados obtidos neste experimento para codornas japonesas, a ração comercial A atende à exigência nutricional destas aves na fase de postura e assegura o melhor desempenho. Além disto, proporciona a melhor qualidade dos ovos produzidos. Contudo, mais experimentos devem ser realizados no intuito de fiscalizar as rações existentes no mercado, para garantir que a composição das mesmas esteja de acordo com os níveis de garantia estabelecidos pelas empresas produtoras. Assim é possível assegurar desempenho satisfatório das codornas, em fase de produção, juntamente com a qualidade dos ovos produzidos.

\section{CONCLUSÃO}

Conclui-se que a ração A possibilitou melhor desempenho das aves mantendo a qualidade dos ovos das mesmas, além de apresentar valores de PB, Ca e EE dentro dos limites divulgados pela empresa em comparação com as outras marcas de ração.

\section{LITERATURA CITADA}

COSTA, F.G.P. Relação entre exigências nutricionais vs Qualidade de ovos de codornas japonesas. In: IV SIMPÓSIO INTERNACIONAL E III CONGRESSO BRASILEIRO DE COTURNICULTURA, 4., 2010, Lavras, MG. Anais... Lavras: Simpósio Internacional de Coturnicultura, 2010. p.50-70.

BERTECHINI, A.G. Situação atual e perspectivas para a coturnicultura no Brasil. In: IV SIMPÓSIO INTERNACIONAL E III CONGRESSO BRASILEIRO DE COTURNICULTURA, 4., 2010, Lavras, MG. Anais... Lavras: 2010. p.09-14.

\section{IBGE. INSTITUTO BRASILEIRO DE} GEOGRAFIA E ESTATÍSTICA. Produção da Pecuária Municipal 2013. Disponível em: < http: www.ibge.gov.br> Acesso em 10 de junho de 2015.

JORDÃO FILHO, J.; SILVA, J.H.V.; SILVA, E.L. et al. Exigência de lisina para poedeiras semipesadas durante o pico de postura. Revista

Brasileira de Zootecnia, v.35, n.4, p.17281734, 2006.

LIMA, R.C.; COSTA, F.G.P.; GOULART, C.C. et al. Exigência de proteína bruta para codornas japonesas (Coturnix coturnix japonica) na fase de postura. Arquivos Brasileiros de Medicina Veterinária e Zootecnia, v.66, n.4, p.1234-1242, 2014. 
MATSUBARA, T.; SAWANO, K. Proteolytic Cleavage of Vitellogenin and Yolk Proteins During Vitellogenin Uptake and Oocyte Maturation in Barfin Flounder (Verasper Moseri). Journal of Experimental Zoology, v.272, p.34-35, 1995.

MURAKAMI, A.E.; GARCIA, E.R.M. Manejo de codornas de postura. In: IV SIMPÓSIO INTERNACIONALCOTURNICULTURA, 2010, Lavras, MG, v.1, p.38. Anais... Lavras:

Universidade Federal de Lavras/NECTA, 2010. 285p.

\section{NATIONAL RESEARCH COUNCIL. Nutrient} requeriments of poultry. 9.ed. Washington (DC): National Academy Press, 1994. 155p.

NERY, V.L.H.; NOVOA, D.M.T.; DURÁN, A.O. et al. Efecto de los niveles de proteína sobre el desempeño de codornices japonesas en fase de postura. Orinoquia, v.17, n.1, p.30-37, 2013.

OST, R.P.; PEIXOTO, R.R. Níveis de energia metabolizável em rações para poedeiras de ovos marrons nas condições de inverno e verão da região de Pelotas-RS. Revista Brasileira de Zootecnia, v.29, n.6, p.2283-2291, 2000.

PECURI, A.; COON, C. Effect of temperature and dietary energy on layer perfomance. Poultry Science, v.70, p.126-138, 1991.

REIS, R.S.; BARRETO, S.L.T.; DE PAULA, E. et al. Níveis de suplementação de colina na dieta de codornas japonesas em postura. Revista

Brasileira de Agropecuária

Sustentável, v.2, n.1, p.118-123, 2012.
SILVA, D.J.; QUEIROZ, A.C. Análise de alimentos (Métodos químicos e biológicos). 3.ed. Viçosa: Editora UFV Universidade Federal de Viçosa, 2002. 235p.

NESHEIM, M.C. Genetic variations in nutrient requirements. World Poultry Science Journal, v.22, p.290-298, 1966.

PASTORE, S.M.; GOMES, P.C.; ROSTAGNO, H.S. et al. Calcium levels and calcium: available phosphorus ratios in diets for white egg layers from 42 to 58 weeks of age. Revista

Brasileira de Zootecnia, v.41, n.12, p.2424$2432,2012$.

UNIVERSIDADE FEDERAL DE VIÇOSA.

Sistema para análise estatística e genética - SAEG, Versão 8.0. Viçosa, MG: Fundação Arthur Bernardes, 2007. 59p. (manual do usuário).

VIANA, G.S. Redução da proteína bruta em rações formuladas com conceito de proteína ideal para galinhas poedeiras leves de 24 a 40 semanas de idade. 2013. Dissertação (Mestrado em Zootecnia) Universidade Federal de Viçosa, Viçosa, 2013.

VIEIRA, D.V.G.; BARRETO, S.L.T.; VALERIANO, M.H. et al. Exigência de cálcio e de fósforo disponível para codornas japonesas de 26 a 38 semanas de idade. Revista Brasileira de Saúde e Produção Animal, v.13, n.1, p.204-213, 2012.

Recebido para publicação em 10/02/2015 e aprovado em 30/07/2015. 